East African Medical Journal Vol. 81 No. 5 May 2004

ASSESSMENT OF CLINICAL CASE-DEFINITION FOR HIV/AIDS IN TANZANIA

W. Amirali, MBBS, Cert. Trop. Med., Medical Department, Shree Hindu Mandal Hospital, Dar es Salaam, Tanzania, C. Moshiro, MSc., Department of Epidemiology and Biostatistics, Muhimbili University College of Health Sciences, Dar es Salaam, Tanzania and K. Ramaiya, MMed., Medical Department, Shree Hindu Mandal Hospital, Dar es Salaam, Tanzania

Request for reprints to: Dr. W. Amirali, 73 Elvira Cresent, London ON N6E 2NI, CANADA

\title{
ASSESSMENT OF CLINICAL CASE-DEFINITION FOR HIV/AIDS IN TANZANIA
}

\author{
W. AMIRALI, C. MOSHIRO and K. RAMAIYA
}

\begin{abstract}
Objective: To evaluate the usefulness of World Health Organisation (WHO's) clinical case-definition (CCD) for AIDS in a private hospital.

Design: A prospective study.

Setting: Shree Hindu Mandal Hospital, Dar es Salaam, Tanzania.

Subjects: A total of 601 patients (> 14 years) were studied from January 1995 to December 1997.

Methods: Using HIV test results as a reference standard, sensitivity, specificity, positive predictive values (PPV) and negative predictive values of signs and symptoms were calculated. Multiple logistic regression was used to determine a set of predictive symptoms and signs. Stepwise logistic regression modelling was used to choose the final model.

Results: The frequently occurring signs and symptoms among the 473 sero-positive patients were fever (226), oral candidiasis (167), weight loss (161), chronic cough (157), diarrhoea (100) and pulmonary tuberculosis in 69 cases. The presence of anorectal lesions and the rarity of pneumocystis carinii pneumonia in this study are important findings. Seven clinical characteristics predicted HIV infection. These included pulmonary tuberculosis $(p=0.009)$, lymphadenopathy $(p=0.007)$, diarrhoea $(p=0.000)$, chronic cough $(p=0.001)$, dermatitis $(p=0.003)$, herpes zoster $(p=0.01)$ and oral candidiasis $(\mathbf{p}=\mathbf{0 . 0 0 0})$.

Conclusions: A greater number of HIV positive patients presented with signs and symptoms different from those proposed by WHO's CCD were observed in this study. With environmental pathogens varying from one geographical region to another and new ones appearing, opportunistic disease cannot be constant in AIDS patients. Therefore, AIDS diagnosis based on clinical case definition alone without at least one positive HIV antibody test is inaccurate and no longer justified.
\end{abstract}

\section{INTRODUCTION}

The human immunodeficiency virus (HIV) which causes acquired immunodeficiency syndrome (AIDS) appeared in the 1980s. The real magnitude of the HIV/ AIDS epidemic in Africa has not been documented but available data and projections suggest that in subSaharan Africa the epidemic remains uncontrolled and is still increasing(1). Deficiency of the immune system renders (HIV) infected patients more susceptible to a wide variety of opportunistic infections and malignancies.

AIDS pandemic has worsened the poor health care situation in developing countries resulting in inadequate treatment being available to its population(2). This and the dire economic situation and political chaos in countries south of Sahara has resulted in patients being seen in greater numbers with late stage HIV/AIDS associated disease.

Since most of the developing countries often lack adequate laboratory facilities, a definition of AlDS based on clinical criteria that would enable clinicians to arrive at this diagnosis with maximum precision was suggested in 1987. Different African countries have evaluated this WHO clinical case definition for AIDS(3) while others have suggested modifications(4-9).

However, diseases associated with HIV infection in different geographical areas may not be the same due to variation in the pathological factors present in the environment and differences in genetic susceptibility of the host(10). Due to lack of diagnostic facilities, some diseases are under reported.

The present study evaluated the usefulness of WHO clinical case definition for $\operatorname{AIDS}(3)$ in a private hospital in Tanzania during a three year period (19951997). The effect of different environmental pathogens on the immunocompromised patients, the need for periodical evaluation and modification of clinical case definition (CCD) in different geographical areas are discussed. 


\section{MATERIALS AND METHODS}

Six hundred and eighteen patients (> 14 years) were studied at the Shree Hindu Mandal Hospital, a private hospital in Dar es Salaam, Tanzania from January 1995 to December 1997. These patients were selected among the in-patient admissions and patients attending outpatient departments of this hospital who underwent HIV serology test based on clinical suspicion of HIV/AIDS. Of these 618 patients studied, 17 cases with incomplete data were excluded and the remaing 601 cases form the basis of the present study.

Using a standardised questionnaire, demographic, clinical and laboratory data of these subjects were recorded. The WHO clinical case definition (World Health Organisation 1988) was examined in this study. HIVl and HIV2 serology test was performed on two occasions with the patient's consent using VIDAS HIV DUO (HIV4). ELFA technique (Enzyme-Linked Fluorescent Assay), bioMerieux sa, Lyon, France. Diagnosis of pulmonary tuberculosis (PTB) was confirmed with chest X-ray and sputum examination for acid fast bacilli (AFB) while pneumocystis carinii pneumonia (PCP) was diagnosed using chest radiographs.

Analysis was done using Stata Statistical Software Version 6.0, Stata Corporation, Texas, USA (1999). Sensitivity, specificity, positive predictive values (PPV) and negative predictive values (NPV) of clinical features were calculated using positive HIV serology as the reference standard. Ages among females and males were compared by t-test. Multiple logistic regression was used to determine a set of predictive symptoms and signs. Variables were included in the initial model if they were associated with HIV infection at $\mathrm{p}<0.05$ in bivariate analysis. Stepwise logistic regression modelling was used to choose our final model. All potential symptoms were fitted in the model with $\mathrm{p}=0.05$ used for removing symptoms from the model. The model's predictive abilities are reported in terms of sensitivity, specificity, PPV and NPV.

\section{RESULTS}

Six hundred and one adult patients were studied. Of these $325(54 \%)$ were men and $276(46 \%)$ were women. The male female ratio was $1.2: 1$. The mean age for men was 36.2 years $(S D=10.35)$ and for women it was 31.4 years $(\mathrm{SD}=9.21)$. The women with HIV infection were significantly younger as compared to the male patients $(p<0.0001)$. The majority of HIV positive patients were seen below the age of 45 years in both sexes. However, the maximum number of HIV positive patients was seen in the 25 - 34 and 35 - 44 year age group among females and males respectively (Table I).

Of these 601 patients, 185 cases met the WHO clinical case definition. Of these 173 cases were sero positive while 12 were sero negative. Of the other 416 patients who did not meet the clinical case definition, 300 and 116 subjects were sero positive and negative respectively. The WHO clinical case definition for AIDS had a low sensitivity of $36.6 \%$, a specificity of $90.6 \%$ and positive predictive value of $93.5 \%$ for diagnosis of HIV infection. The difference between positive predictive value and negative predictive value was $65.6 \%$ (Table 2).

Table 1

Age and sex distribution of HIV sero-positive and negative patients

\begin{tabular}{|c|c|c|c|c|}
\hline \multirow{2}{*}{$\begin{array}{l}\text { Age } \\
\text { Groups (years) }\end{array}$} & \multicolumn{2}{|c|}{ Males } & \multicolumn{2}{|c|}{ Females } \\
\hline & HIV+ve $(\%)$ & HIV-ve $(\%)$ & HIV+ve $(\%)$ & HIV-ve $(\%)$ \\
\hline $15-24$ & 13 & 16 & 34 & 16 \\
\hline $25-34$ & 87 & 41 & 127 & 26 \\
\hline $35-44$ & 99 & 7 & 41 & 7 \\
\hline $45-54$ & 44 & 4 & 14 & 2 \\
\hline $55-64$ & 4 & 1 & 3 & 3 \\
\hline $65+$ & 5 & 4 & 2 & 1 \\
\hline & 252 & 73 & 221 & 55 \\
\hline
\end{tabular}

Table 2

Assessment of WHO clinical case definition of AIDS in adults

\begin{tabular}{|c|c|c|c|}
\hline \multirow{2}{*}{$\begin{array}{l}\text { Patients } \\
\text { meeting } \\
\text { criteria* }\end{array}$} & \multicolumn{2}{|c|}{$\begin{array}{l}\text { HIV status of patients } \\
\text { Studied }\end{array}$} & \multirow[t]{2}{*}{ Total } \\
\hline & Positive & Negative & \\
\hline Yes & 173 & 12 & 185 \\
\hline \multirow[t]{2}{*}{ No } & 300 & 116 & 416 \\
\hline & 473 & 128 & 601 \\
\hline
\end{tabular}

* Two major criteria and one minor criterion or a diagnosis of Kaposi's sarcoma or cryptococcal meningitis. Sensitivity $=36.6 \%$, Specificity $=90.6 \%$, Positive predictive value $=93.5 \%$, Negative predictive value $=27.9 \%$ 
Table 3

Sensitivity, specificity and positive and negative predictive value of signs and symptoms for HIV infection

\begin{tabular}{|c|c|c|c|c|c|}
\hline $\begin{array}{l}\text { Clinical } \\
\text { Characteristic }\end{array}$ & $\begin{array}{l}\mathrm{HIV}+\mathrm{ve} \\
\text { (No.) }\end{array}$ & Sensitivity $^{1}$ & Specificity $^{2}$ & $\begin{array}{l}\text { Positive } \\
\text { predictive } \\
\text { value }^{3}\end{array}$ & $\begin{array}{l}\text { Negative } \\
\text { predictive } \\
\text { value }^{4}\end{array}$ \\
\hline Fever $>1 \mathrm{mo}$ & 226 & 47.4 & 83.3 & 91.5 & 30.3 \\
\hline Oral candidiasis & 167 & 35.0 & 97.7 & 98.2 & 29.1 \\
\hline Weight loss $>10 \%$ & 161 & 33.8 & 90.8 & 93.1 & 27.2 \\
\hline $\mathrm{Ch}$ cough $>1 \mathrm{mo}$ & 157 & 32.9 & 91.5 & 93.5 & 27.1 \\
\hline Diarrhoea >1 mo & 100 & 21.0 & 97.7 & 97.1 & 25.2 \\
\hline Pul. Turberculosis & 69 & 14.5 & 98.5 & 97.2 & 23.9 \\
\hline Dermatitis & 57 & 11.9 & 98.5 & 96.6 & 23.4 \\
\hline Lymphadenopathy & 46 & 9.6 & 97.7 & 93.9 & 22.8 \\
\hline Herps zoster & 30 & 6.3 & 99.2 & 96.8 & 22.4 \\
\hline Kaposis sarcoma & 25 & 5.2 & 99.2 & 96.2 & 22.2 \\
\hline Wasting >1 mo & 25 & 9.0 & 93.1 & 73.5 & 32.4 \\
\hline Anorectal lesions & 23 & 4.8 & 100.0 & 100.0 & 22.2 \\
\hline Confusion & 23 & 4.8 & 97.7 & 88.5 & 21.9 \\
\hline Pyoderma & 15 & 3.1 & 99.2 & 90.9 & 21.8 \\
\hline Cryptococcal Meningitis & 11 & 2.3 & 99.2 & 100.0 & 21.7 \\
\hline Pleural effusion & 10 & 2.1 & 99.2 & 90.0 & 21.4 \\
\hline Pericarial effusion & 9 & 1.9 & 100.0 & 90.9 & 21.6 \\
\hline Amonorrhoea & 9 & 1.9 & 99.2 & 90.5 & 21.5 \\
\hline Dysphagia & 7 & 1.5 & 99.2 & 87.5 & 21.5 \\
\hline Genital ulcers & 6 & 1.3 & 99.2 & 85.7 & 21.4 \\
\hline Pyomyositis & 5 & 1.0 & 100.0 & 100.0 & 21.5 \\
\hline Bells palsy & 3 & 0.6 & 100.0 & 100.0 & 21.5 \\
\hline ENT infection & 3 & 0.6 & 100.0 & 100.0 & 21.5 \\
\hline PID & 3 & 0.7 & 100.0 & 100.0 & 23.5 \\
\hline PCP & 2 & 0.4 & 99.2 & 66.7 & 21.3 \\
\hline Arthritis & 1 & 0.2 & 98.4 & 33.3 & 21.1 \\
\hline
\end{tabular}

1. percentage of HIV sero positive patients with symptoms or signs, 2. percentage of HIV sero negative patients without symptoms or signs, 3. percentage of patients with symptoms or signs who were HIV seropositive, 4. percentage of patients without symptoms or signs who were HIV seronegative

Table 4

Proposed clinical case definition (CCD) modification

\begin{tabular}{llll}
\hline Clinical Characteristic & Odds ratios & 95\%CI & p-value \\
\hline Pulmonary Tuberculosis & & & 0.009 \\
Lymphadenopathy & 7.1 & $1.6,30.9$ & 0.007 \\
Diarrhoea & 5.5 & $1.6,18.8$ & 0.000 \\
Chronic cough & 8.9 & $2.7,29.7$ & 0.001 \\
Dermatitis & 3.2 & $1.6,6.2$ & 0.003 \\
Herpes zoster & 8.9 & $2.1,38.6$ & 0.01 \\
Oral candidiasis & 14.3 & $1.9,108.9$ & 0.000 \\
\hline
\end{tabular}

Sensitivity $=73.5 \%$, Specificity $=33.5 \%$, Positive predictive value $=93.9 \%$, Negative predictive value $=47.3 \%$

Of the 12 HIV sero negative patients meeting the WHO clinical case definition, nine had weight loss, 12 fever, seven cough, four asthenia, diarrhoea, lymphadenopathy pulmonary tuberculosis and thrush was observed in two each, while herpes zoster, Kaposi's sarcoma, cryptococal meningitis and pleural effusion was seen in one each.
The commonest individual signs and symptoms among the 473 sero-positive patients were fever in 226 , oral candidiasis in 167 , weight loss in 161 , chronic cough in 157 and diarrhoea in 100 patients. Pulmonary tuberculosis was observed in 69 cases. The average number of signs and symptoms present in the 473 sero- 
positive patients was 3 (range 1-8). The presence of anorectic lesions and the rarity of pneumocystis carinii pneumonia in this study are important findings. The sensitivity, specificity, positive and negative predictive values for different signs and symptoms are also shown in Table 3.

Multivariate analysis for a proposed modification of the CCD showed seven clinical characteristics predicted HIV infection independently in this population. These were pulmonary tuberculosis, lymphadenopathy, diarrhoea, chronic cough dermatitis, herpes zoster and oral candidiasis. The sensitivity and specificity of these seven clinical features collectively were $73.5 \%$ and $83.5 \%$ respectively. Their positive and negative predictive values were $93.9 \%$ and $47.3 \%$ respectively. Although weight loss $(\mathrm{p}<0.001)$ and fever $(\mathrm{p}<0.001)$ were not included in the final model due to their high colinearity with the other predictors yet were strong independent predictors of HIV infection (Table 4).

\section{DISCUSSION}

Infection with human immunodeficiency virus is common and the prevalence of this disease is increasing in sub-Saharan Africa particularly among the sexually active age group in both sexes (Table 1). Inadequate laboratory facilities available for diagnosing HIV/AIDS has resulted in an under reporting of this disease in an African populatio (11). WHO proposed a CCD that could facilitate diagnosis of AIDS in such a situation.

In the present study WHO clinical case definition for AIDS(3) had a low sensitivity (36.6\%) with a high predictive value $(93.5 \%)$ and a specificity of $90.6 \%$ for diagnosis of HIV infection (Table 2). It has been suggested that positive predictive value is important for the clinician(12). Interestingly in the present study $63.4 \%$ patients were HIV positive but with different signs and symptoms than those suggested by WHO in its clinical case definition(3). The wide range of signs and symptoms with high predictive values above $90 \%$ in the majority of these HIV positive patients would suggest that there is a need to review and revise the clinical case definition in different geographical regions periodically as environmental pathogens vary and new ones may appear altering the opportunistic disease of a patient with AIDS. The presence of anorectic lesions in a heterosexual society suggests a change in sexual behaviour whereas the rarity of pneumocystis carinii pneumonia (PCP) could be due to under diagnosis of (PCP) or the relative absence of the causative factor in the environment (Table 3).

In our study the proposed CCD modification (Table 4) demonstrated a higher sensitivity $(73.5 \%)$, even higher positive predictive value $(93.9 \%)$ and a slightly lower specificity $(83.5 \%)$ as compared to WHO (CCD).
A phenomenal change has occurred in the clinical characteristics or HIV/AIDS patients as seen in this study with a higher sensitivity and predictive value as compared to a previous Tanzanian study(8). This would further support the need to validate CCD periodically.

Combinations of clinical features could guide selection of patients for HIV serologic testing and could be useful in reducing costs incurred by the health delivery system in financially constrained developing countries. However early detection of HIV infection requires sensitive criteria(8). Therefore one should not negate the need for a judicial determination of HIV serology status. The prevalence of HIV infection in a population confirmed serologically is also of public health importance.

As with WHO (CCD) the false positive results recorded in our study was also high. Therefore, AIDS diagnosis based on clinical case definition alone without at least one positive HIV antibody test is inaccurate and no longer justified.

\section{REFERENCES}

1. Piot, P., Kapita, B.M., Were, J.B.O., Laga, M. and Colebunders, R.L. AIDS in Africa: The first decade and challenges for the 1990s. AIDS. 1991; 5(Suppl 1):1-5..

2. The World Bank: Sub-Saharan Africa. From crisis to sustainable growth. Washington DC. The World Bank. 1989.

3. World Heath Organization. Acquired immunodeficieny syndrome (AIDS), 1987 revision of the CDC/WHO case defination for AIDS. Wklyl Epid. Rec. 1988; 63:1-8.

4. Colebunders, R., Mann, J.M., Francis, H., et al. Evaluation of a clinical case-definition of acquired immunodeficiency syndrome in Africa. Lancet. 1987; 1:492-494.

5. Widy-Wirski, R., Berkley, S., Downing, R., et al. Evaluation of the WHO clinical case definition for AIDS in Uganda. JAMA. 1988; 260:3286-3289.

6. Nelson, A.M., Perriens, J.H., Kapita, B., et al. A clinical and pathological comparison of the WHO and CDC case definitions for AIDS in Kinshasa, Zaire: is passive surveillance valid? AIDS. 1993; 7:1241-1245.

7. Ankrah, T.C., Roberts, M.A., Antwi, P., et al. The African AIDS case definition and HIV serology in medical inpatients at Komfo Anokye Teaching Hospital, Kumasi, Ghana. West. Afr. J. Med. 1994; 13:98-101.

8. Miller, W.C., Thielman, N.M., Swai, N., et al. Diagnosis and screening of HIV/AIDS using clinical criteria in Tanzanian adults. J. Acquir. Immune. Defic. Syndr. Hum. Retrovirol. 1995; 9:408-414.

9. Pallangyo, K.J., Mbaga, I.M., Mugusi, F., et al. Clinical case definition of AIDS in African adults. Lancet. 1987; 2:972.

10. Colebunders, R.L. and Latif, A.S. Natural history and clinical presentation of HIV-I infection in adults. AIDS 1991; 5(supp 1):103-112.

11. National AIDS control programme. HIV/AIDS/STD surveillance. Ministry of health, Tanzania Mainland, epidemiology unit, NACP: Dec. Report No. 10. 1995.

12. Campbell, M.J., and Machill, D. Medical statistics: a common sense approach. 2nd edition. John Willey and Sons, 1993. 